\title{
Neonatal Atrial Flutter Approach: A Case Series
}

\author{
Abordagem de Flutter Atrial Neonatal: Uma Série de Casos \\ Fernanda Pessa Valente1, Gustavo Henrique Belarmino Góes ${ }^{2, *}$, Caroline Bernardi Fabro², \\ Afonso Luiz Tavares Albuquerque ${ }^{3}$, Dário Celestino Sobral Filho²
}

ORCID IDS

Valente FP (iD https://orcid.org/0000-0002-9713-6988

Góes GHB (D) https://orcid.org/0000-0003-3366-1182

\begin{abstract}
Objective: This study set out to analyze the therapeutic options of patients with neonatal atrial flutter (AFL), considering the diagnostic methods available and the prognosis of these patients. Methodology: A retrospective study was performed by reviewing the medical records of a series of seven patients with atrial fibrillation (AF) diagnosed during fetal or neonatal period. The follow-up time of these patients ranged from 7 months to 3 years and 8 months (mean: 1 year). The clinical data for the diagnosis included sustained heart rate greater than 180 bpm, which was confirmed in all patients by a 12-lead electrocardiogram. Results: Four (57.1\%) of the 7 patients studied were male. Most of the patients revealed cardiac arrhythmia during the intrauterine period when screened by fetal ultrasound in the third trimester of gestation (5 patients, i.e. 71.2\%). Only the mother of Patient 2 was administered digoxin before childbirth. The atrial rate of the tachyarrhythmia revealed a mean of 375 bpm, with an increase of up to $500 \mathrm{bpm}$. Atrioventricular conduction presented a 2:1 ratio in all patients, with variations of 3:1 and 4:1 observed in Patients 1,3 and 6 . The ventricular rate ranged from 188 to $250 \mathrm{bpm}$. All patients revealed typical and counter-clockwise electrocardiogram characteristics. Synchronized electrical cardioversion was the treatment of choice in 6 patients (85.7\%), with a dose of $1 \mathrm{~J} / \mathrm{kg}$. Conclusion: Early diagnosis, prior treatment, and synchronized electrical cardioversion indicate an excellent prognosis, and prolonged maintenance treatment may be unnecessary.
\end{abstract}

KEYWORDS: Cardiac arrhythmia; Supraventricular; Neonatal.

\author{
Albuquerque ALT (D) https://orcid.org/0000-0003-3801-9201 \\ Fabro CB (D) https://orcid.org/0000-0003-4522-8810 \\ Sobral Filho DC (D) https://orcid.org/0000-0002-5301-7741
}

\section{RESUMO}

Objetivo: Este estudo teve como objetivo analisar as opções terapêuticas dos pacientes com flutter atrial (FLA) neonatal, considerando os métodos diagnósticos disponíveis e o prognóstico desses pacientes. Metodologia: Foi realizado um estudo retrospectivo através da revisão dos prontuários de uma série de sete pacientes com fibrilação atrial (FA) diagnosticada durante o período fetal ou neonatal. O tempo de seguimento desses pacientes variou de 7 meses a 3 anos e 8 meses (média: 1 ano). Os dados clínicos para o diagnóstico incluíram frequência cardíaca sustentada superior a 180 bpm, que foi confirmada em todos os pacientes por um eletrocardiograma de 12 derivações. Resultados: Quatro $(57,1 \%)$ dos sete pacientes estudados eram do sexo masculino. A maioria dos pacientes revelou arritmia cardíaca durante o período intrauterino, quando examinados por ultrassom fetal no terceiro trimestre de gestação (5 pacientes, ou seja 71,2\%). Apenas à mãe do Paciente 2 foi administrada digoxina antes do parto. A taxa atrial da taquiarritmia revelou uma média de 375 bpm, com um aumento de até 500 bpm. A condução atrioventricular apresentou uma relação de 2:1 em todos os pacientes, com variações de 3:1 e 4:1 observadas nos Pacientes 1, 3 e 6. A frequência ventricular variou de 188 a $250 \mathrm{bpm}$. Todos os pacientes revelaram características típicas e anti-horárias do eletrocardiograma. A cardioversão elétrica sincronizada foi o tratamento de escolha em 6 pacientes $(85,7 \%)$, com uma dose de $1 \mathrm{~J} / \mathrm{kg}$. Conclusão: Diagnóstico precoce, tratamento prévio e cardioversão elétrica sincronizada indicam um excelente prognóstico, e o tratamento de manutenção prolongada pode ser desnecessário.

PALAVRAS-CHAVE: Arritmia cardíaca; Supraventricular; Neonatal.

1.Instituto de Medicina Integral Professor Fernando Figueira - Recife (PE), Brazil.

2.Universidade de Pernambuco - Faculdade de Ciências Médicas - Recife (PE), Brazil.

3.Pronto Socorro Cardiológico de Pernambuco - Recife (PE), Brazil.

Received: Jan, 132020 | Accepted: Jan. 27, 2020

*Correspondence author: gustavogoesmt@gmail.com

Section Editor: José Tarciso Medeiros de Vasconcelos 


\section{INTRODUCTION}

Atrial flutter (AFL) is defined as a supraventricular tachyarrhythmia that originates from a macroreentreted circuit, most often in the right atrium, generating continuous atrial electrical activity. The AFL may be typical, which is the most frequent type, when the cavotricuspid isthmus is part of its circuit; or atypical, when this anatomical region is excluded. Several authors also refer to the latter as macroreentrant atrial tachycardia. The typical AFL may be counter-clockwise when the depolarization of the atrial septum occurs from the bottom, or clockwise in the reverse situation. Patients at an increased risk for AFL include elderly people and those with structural heart disease, heart failure, or obstructive lung disease. The atrial rate ranges from 240 to $340 \mathrm{bpm}$ and the ventricular rate depends on the degree of blockade at the atrioventricular node, resulting in variable atrioventricular relationships, such as $1: 1$, 2:1 (most common), 3:1, or 4:1 ${ }^{1}$.

The arrhythmogenic mechanism in neonates is the same. However, since most neonates reveal a structurally normal heart, the etiology is not well defined. The atrial rate exhibits higher values in neonates than in adults, with a mean of $440 \mathrm{bpm}$. In older children, it is around $300 \mathrm{bpm}$. The atrioventricular (AV) ratio also varies, with 2:1 being the most frequent ${ }^{2}$.

Cardiac arrhythmias are found in about $2 \%$ of fetuses. In this population, they are considered a risk factor and are one of the main indications for fetal echocardiography. Suspected fetal arrhythmia includes the following: sustained heart rate (HR) above $180 \mathrm{bpm}$, repetitive irregular heartbeat, and unexplained fetal hydrops. In all cases, the exclusion of underlying cardiac injury is mandatory ${ }^{3}$.

The absence of multicenter studies in the pediatric population indicates a lack of accurate data related to the incidence, etiology, risk of thromboembolism, and evidence-based therapeutic measures for the treatment of $\mathrm{AFL}^{4}$.

\section{METHODS}

A retrospective study was carried out by reviewing the charts of a series of 7 patients with AFL diagnosed during the fetal or neonatal period. The follow-up period of these patients ranged from 7 months to 3 years and 8 months (mean: 1 year). The patients were born in reference hospitals for neonatology in the city of Recife, Brazil, and were transferred to the referral centers in pediatric cardiology after a diagnosis of tachyarrhythmia. The clinical data for diagnosis included sustained heart rate greater than $180 \mathrm{bpm}$. The diagnosis of AFL was confirmed in all patients by means of a 12-lead electrocardiogram (ECG).

\section{RESULTS}

Four $(57.1 \%)$ of the 7 patients studied were male (Table 1). Most of them revealed cardiac arrhythmia during the intrauterine period, when screened by fetal ultrasound in the third trimester of gestation (5 patients, i.e. 71.2\%). Even when an intrauterine arrhythmia was susceptible, fetal echocardiograms were not performed because of the advance gestational age. During gestation, the following complications were observed: gestational diabetes, pyelonephritis, polyhydramnios and prematurity at 36 weeks (Patient 4), urinary tract infection near labor and prematurity at 32 weeks (Patient 5), alcoholism and smoking at 39 weeks (Patient 7). Only Patient 2 was administered digoxin $(0.25 \mathrm{mg} /$ day $)$ prior to delivery.

At birth, only Patient 5 was considered to have mild hypoxia, according to the Apgar score, and was administered crystalline penicillin and intravenous gentamicin for 7 days. Signs of heart failure were absent in the patients at birth or at the time of arrhythmia diagnosis. Transthoracic echocardiography was performed in all patients, with atrial septal defect (ASD) as the most frequent congenital heart disease (4 patients, i.e. 57.1\%), with hemodynamic repercussion occurring only in Patient 7. All patients revealed normal ventricular function (Table 2).

Considering the electrocardiographic characteristics, the atrial rate of the tachyarrhythmia revealed a mean of $375 \mathrm{bpm}$, with an increase of up to $500 \mathrm{bpm}$ (Fig. 1). Atrioventricular conduction presented a 2:1 ratio in all patients, with variations of 3:1 and 4:1 observed in Patients 1, 3 and 6. The ventricular rate ranged from 188 to $250 \mathrm{bpm}$. All patients revealed typical and counterclockwise ECG characteristics. 
Table 1. Clinical characteristics of atrial flutter patients.

\begin{tabular}{|c|c|c|c|c|}
\hline Patients & Age at diagnosis (SCM) & Gender & Neonatal complications & Heart failure \\
\hline 1 & 37 weeks & Female & No & No \\
\hline 2 & 37.2 weeks & Male & No & No \\
\hline 3 & 37.3 weeks & Male & No & No \\
\hline 4 & 8 h of life (36 weeks) & Female & GDM + pyelonephritis + polyhydramnios + prematurity & No \\
\hline 5 & 32 weeks & Male & Treated UTI + prematurity + low birth weight & No \\
\hline 6 & 6 days & Female & No & No \\
\hline 7 & 72 h of life (39.2 weeks) & Male & Alcohol consumption + smoking + SGA & No \\
\hline
\end{tabular}

SCM: Somatic Capurro's method; GDM: gestational diabetes mellitus; UTI: urinary tract infection; SGA: small for gestational age.

Table 2. Congenital heart disease associated with atrial flutter and diagnosed by transthoracic echocardiogram.

\begin{tabular}{ccc}
\hline Patients & Cardiopatia congênita & Gender \\
\hline $\mathbf{1}$ & PFO & Female \\
$\mathbf{3}$ & PFO + RA enlargement & Male \\
$\mathbf{4}$ & Ostium secundum type IAC \\
$\mathbf{5}$ & Ostium secundum type IAC & Female \\
$\mathbf{6}$ & ASA + small ostium secundum type IAC + small PDA & Male \\
$\mathbf{7}$ & Ostium secundum type IAC + RA and RV enlargement & Female \\
\hline
\end{tabular}

PFO: Patent foramen ovale; RA: Right atrial; IAC: Interatrial communication; ASA: Atrial septum aneurysm; PDA: Persistent ductus arteriosus; RV: Right ventricle.

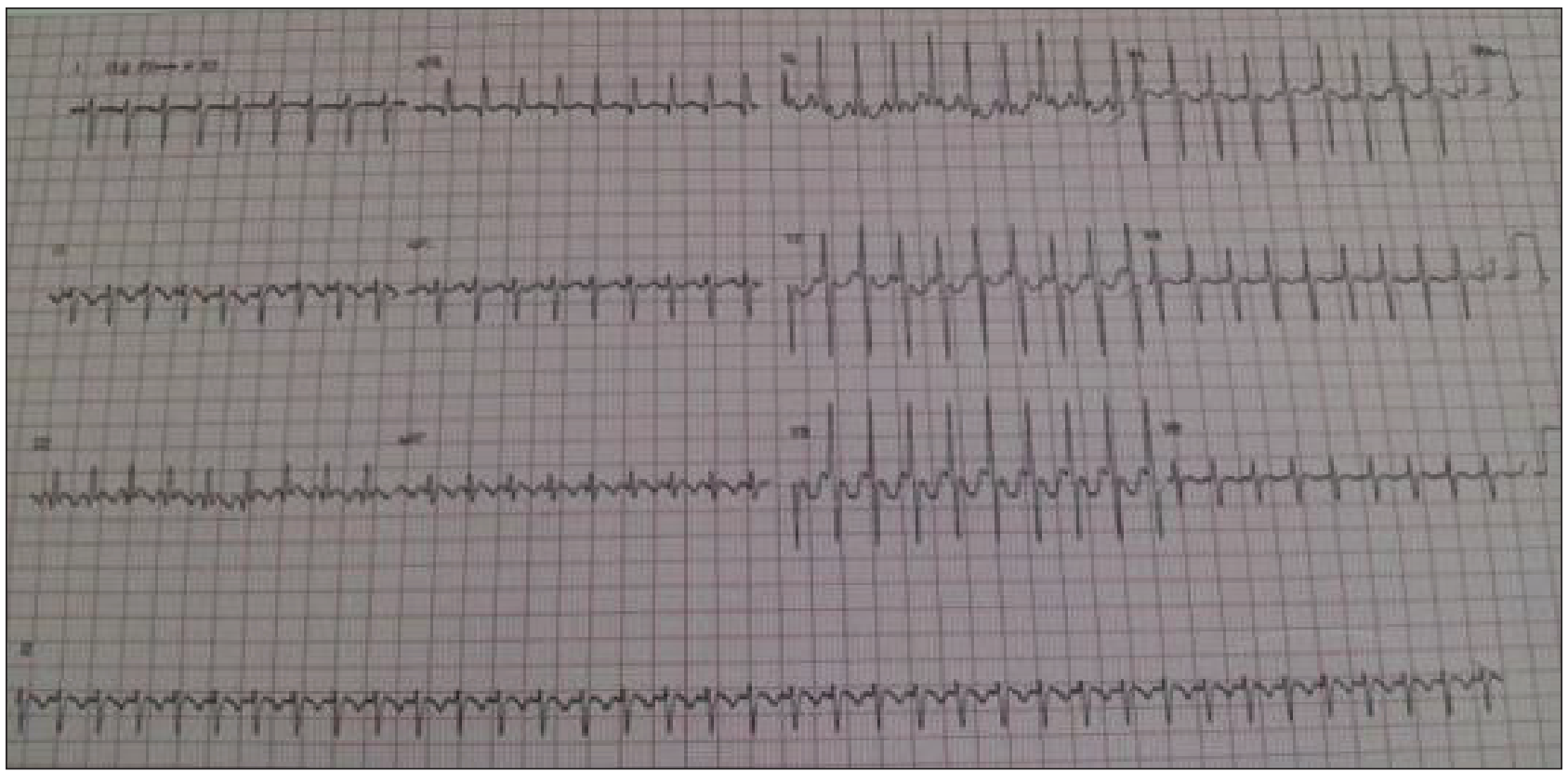

Figure 1. Electrocardiogram showing an atrial flutter with an atrial frequency of approximately $500 \mathrm{bpm}$, atrioventricular ratio 2:1 and a ventricular rate of around $250 \mathrm{bpm}$ (Patient 4).

Synchronized electrical cardioversion (SECV) was the treatment of choice in 6 patients $(85.7 \%)$, with a dose of $1 \mathrm{~J} / \mathrm{kg}$. It was performed in the initial $24 \mathrm{~h}$ after birth in 3 patients (Patients 1, 2 and 4). Patient 3 received SECV $48 \mathrm{~h}$ after birth; Patient 6 on the 6 th day after birth; and Patient 7 within $72 \mathrm{~h}$ after birth. Only Patient 4 presented respiratory depression during the procedure, requiring orotracheal intubation and reapplication of SECV, with the same dose as the first, this time with a positive result. The patient was extubated within 
$24 \mathrm{~h}$ without further complications. After SECV, all patients were given intravenous amiodarone at a dose of $10 \mathrm{mg} / \mathrm{kg} /$ day, and after $48 \mathrm{~h}$ the dosage was reduced to $5 \mathrm{mg} / \mathrm{kg} /$ day orally. Only Patient 5 was submitted to pharmacological treatment: initially with adenosine (2 doses of $0.1 \mathrm{mg} / \mathrm{kg}$ each); (0.01 mg/kg/day); and subsequently with amiodarone (dose $10 \mathrm{mg} / \mathrm{kg} \mathrm{EV}$ and maintenance $5 \mathrm{mg} / \mathrm{kg} /$ day EV). On the third day after birth, using amiodarone, the sinus rhythm was reversed. Only Patient 1 presented recurrence of tachyarrhythmia after $2 \mathrm{~h}$ of SECV. During this period, the dose of amiodarone was increased to $15 \mathrm{mg} / \mathrm{kg} /$ day intravenously and a further SECV was scheduled; however, there was a reversion to sinus rhythm after $14 \mathrm{~h}$ without the requirement for cardioversion. Anticoagulation therapy was not performed prior to SECV in any of the patients.

Three patients (42.9\%) presented a prolonged PR interval on the ECG after cardioversion (Table 3). No additional arrhythmias were seen after restoration of sinus rhythm. All patients were discharged on pharmacological treatment with amiodarone (dose $5 \mathrm{mg} / \mathrm{kg} /$ day), with an average hospital stay of 7 days, ranging from 3 to 12 days. The maintenance treatment with amiodarone ranged from 1 to 6 months, with an average of 3 months. Due to the short duration of treatment, thyroid function tests were not performed. The bloodspot test was also without changes. Currently, all patients are followed as outpatients, asymptomatic, with adequate neuropsychomotor development and with no new episodes of AFL.

Table 3. Electrocardiographic changes after synchronized electrical cardioversion.

\begin{tabular}{cc}
\hline Patients & Changes after SECV \\
\hline 1 & No \\
2 & PRi enlargement (130 ms) \\
3 & PRi enlargement (120 ms) \\
4 & No \\
5 & PRi enlargement (140 ms) \\
6 & No \\
$\mathbf{7}$ & No \\
\hline
\end{tabular}

SECV: synchronized electrical cardioversion; PRi: PR interval.

\section{DISCUSSION}

Currently, AFL can be grouped into two different clinical situations in the pediatric population: in the fetal, neonatal, and infantile periods, usually with a structurally normal heart; and in older children, with associated structural heart disease (with or without cardiac surgery $)^{2,5}$.

Considering the assumption of cardiac arrhythmia in the fetus, the ideal gestational age for fetal echocardiography is probably between 16 and 22 weeks, since the intracardiac anatomy should also be evaluated to exclude the presence of congenital heart disease ${ }^{3,6}$, which is practically nonexistent, as demonstrated by the patients who were evaluated predominantly from the 36 th week of gestation.

Once fetal tachyarrhythmia has been confirmed, the factors that determine the course of treatment in utero are gestational age, associated congenital heart disease, symptoms of heart failure and, particularly, the presence of hydrops and the duration of tachycardia ${ }^{7}$. Simpson et al. reported that $65 \%$ of tachycardias in fetuses were persistent, and the incidence of hydrops was $41 \%{ }^{8}$. Only the mother of one patient in this study was administered digoxin $(0.25 \mathrm{mg} /$ day $)$ before delivery, a first-line drug for nonhydrophobic fetuses, as reported by Batra et al. ${ }^{9}$. In fecal fetuses, flecainide is the drug of choice ${ }^{9}$ Lisowski et al. ${ }^{10}$, in a retrospective study with 45 patients with perinatal ABI (44 with fetal diagnosis and 1 immediately after birth), evaluated the efficacy of intrauterine treatment. They concluded that digoxin failed to prevent the recurrence of AFL in a quarter of the patients, whereas no recurrences were observed in the sotalol group. Patients in whom the arrhythmia recurred at birth were treated with CVES, with no subsequent recurrences. In cases of persistent arrhythmia, there were complications such as hydrops and neurological impairment, emphasizing the importance of early treatment of this arrhythmia in relation to the prognosis of the patients; however, in the cases that reverted to sinus rhythm, maintenance drug therapy was unnecessary.

Atrial flutter in fetuses and newborns is, in general, clinically well tolerated ${ }^{8}$. The atrial rate in such patients exhibits higher values than in adults, with a mean of $440 \mathrm{bpm}$, or up to $500 \mathrm{bpm}^{2,8}$. Patients in the present study revealed a heart rate ranging from 188 to $250 \mathrm{bpm}$, with a mean of $375 \mathrm{bpm}$, close to that described in the literature, although in one of the patients it increased to $500 \mathrm{bpm}$. 
Patients with this condition are usually asymptomatic, and if the AV ratio displays a high degree of blockade, the ventricular rate will be close to normal values for the age group in question. Alternatively, if the AV ratio is $1: 1$, cardiovascular impairment may occur and even cause mortality ${ }^{8}$. The most common AV ratio is $2: 1$ (75\% of cases); consequently, the ventricular rate varies from 150 to $250 \mathrm{bpm}$ in the majority of patients ${ }^{4}$. Moreover, all patients revealed a higher frequency of the $2: 1$ ratio, although three patients had episodes of $3: 1$ and $4: 1$ ratio. In agreement with the literature, the ventricular rate of our study patients ranged from 188 to $250 \mathrm{bpm}$.

The most frequent congenital heart defects associated with AFL are atrial septal defects, atrial septal aneurysm and Ebstein's disease ${ }^{5}$. Similar results were observed in the present study, the most frequent defects being patent foramen ovale and CIA ostium secundum, each of which was separately present in four patients. Nevertheless, in 1985, Garson Jr. et al. ${ }^{11}$ conducted a multicenter study in Houston, Texas, comprising 380 patients diagnosed with AFL, aged between 1 and 25 years, in which only $8 \%$ revealed structural heart disease, most frequently by transposition of the great arteries, univentricular hearts, defects of the interatrial septum, pulmonary stenosis, and tetralogy of Fallot, atrial dilatation, being the main risk factor associated with AFL. This discrepancy among the results can be attributed to the fact that the authors included several adult patients, in whom the pathophysiology of AFL is apparently different from the congenital or neonatal cases.

Although the first-line therapy for AFL was pharmacological (digital, amiodarone and quinidine) until the 1990s, , $^{3,412-15}$, the SECV is currently considered to be the gold standard treatment ${ }^{4,16}$. This change was reflected in this study, in which $85.7 \%$ of the patients were submitted to SECV with $1 \mathrm{~J} / \mathrm{kg}$, followed by intravenous amiodarone $(10 \mathrm{mg} / \mathrm{kg} /$ day $)$. Only one patient was treated with medication: initially adenosine, followed by $\mathrm{C}$-delayside, and subsequently amiodarone. Some authors also recommend that, if the ventricular function is normal and the patient is asymptomatic, SECV can be delayed for $24 \mathrm{~h}$, since $25 \%$ of AFL can revert spontaneously ${ }^{4}$. Texter et al. ${ }^{16}$ studied a review with 50 patients aged less than 1 year, diagnosed with FLA at birth and without previous cardiac surgery, followed at the Texas Children's Hospital for a period of 25 years. They concluded that the diagnosis of FLA occurred more frequently in the first two days after birth and that no association was observed with congenital heart disease. Synchronized electrical cardioversion was the most effective treatment for attaining sinus rhythm. They also established that chronic AFL has a potential risk of cardiovascular impairment, since signs of heart failure would be related to the prolonged duration of tachyarrhythmia. In the absence of structural heart disease, if treated early, AFL has a low risk of recurrence, with an excellent prognosis and no requirement for chronic antiarrhythmic therapy.

According to the Brazilian Guidelines for Cardiac Arrhythmias in Children and Congenital Heart Disease ${ }^{17}$, AFL corresponds to approximately $30 \%$ of fetal tachyarrhythmias. In addition, intrauterine treatment depends on the presentation of tachyarrhythmia (sustained or unsustained) and its hemodynamic repercussion, with varying degrees of heart failure, ventricular dysfunction and even fetal hydrops. Intermittent and clinically uninterrupted pictures may be maintained with close clinical monitoring of the fetus. Occasionally, the use of maternal antiarrhythmic medications is indicated. When used in combination with the ancillary route, sotalol revealed a $50-80 \%$ rate of reversion to a sinus rhythm, being thus regarded as a safe drug; however, the patient should remain hospitalized, with QT interval monitoring due the drugs proarrhythmic effect. Digoxin and amiodarone are the other possible options, the former in order to increase the degree of AV block, thereby decreasing the ventricular response. Bringing forward the children-birth should be considered if the mother is already close to term (multiprofessional evaluation). After delivery, the treatment should be individualized, with CVES as the best therapeutic option.

Part of the data from the series of cases under study corresponded to the data found in the literature; however, due to the small number of cases, it was not possible to identify the common risk factors associated with arrhythmia. All cases were classified as congenital AFL, confirmed by 12-lead ECG. The most frequent heart disease was ostium secundum atrial septal defect; however, this finding was not considered a risk factor for tachyarrhythmia, since hemodynamic repercussion was found in only one patient, while in another the echocardiogram confirmed that there was no associated 
structural heart disease. The treatment of choice for reversion to sinus rhythm was SECV, used in six patients. This method proved to be safe and effective, since only one patient had transient respiratory depression. There was only one recurrence, but that reverted to sinus rhythm with the use of amiodarone. No further arrhythmias occurred and the patients presented good progress throughout the clinical follow-up.

Atrial flutter remains an uncommon arrhythmia in the pediatric population, with distinct clinical forms depending on the age group. Its clinical course, mode of presentation, therapeutic approach, and prognosis are different from those of older children and adults.

In intrauterine life, the diagnosis is still made by means of the fetal echocardiogram, and confirmation after birth is performed by 12-lead ECG. The diagnosis is usually made in the third trimester of gestation, and is more frequent in males. Atrial flutter usually presents a benign progression with no occurrence of cardiac insufficiency or hydropsy, prepartum treatment being the exception.

In general, the atrial rate of tachyarrhythmia does not exceed $500 \mathrm{bpm}$, and the most prevalent atrioventricular conduction rate is $2: 1$. The ventricular rate reaches a maximum of $250 \mathrm{bpm}$, and the PR interval can be prolonged in up to $50 \%$ of cases. Synchronized electrical cardioversion is the preferred treatment, since it is a safe and effective method.

The present study has certain limitations, because it is retrospective and observational. From the outset the clinical and diagnostic research was conducted exclusively by the same group of investigators, thus reducing any possible biases.

Future multicenter studies are necessary to better identify the etiology, incidence, and risk factors for flutter, in addition to promoting evidence-based therapeutic measures in these patients.

\section{CONCLUSION}

Diagnosis, early treatment, and synchronized electrical cardioversion are conducive to an excellent prognosis, and long-term maintenance treatment may be unnecessary.

\section{REFERENCES}

1. Issa ZF, Miller JM, Zipes DP. Typical atrial flutter. In: Clinical arrhythmology and electrophysiology. A companion to Braunwald's Heart Disease. Philadelphia: Elsevier/Saunders; 2012. p. 239-259.

2. Wren C. Atrial Flutter. In: Concise guide to pediatric arrhythmias. 1st ed. Oxford: Wiley-Blackwell; 2011. p. 40-42.

3. Gulletta S, Rovelli R, Fiori R, Bella PD. Multiple external electrical cardioversions for refractory neonatal atrial flutter. Pediatr Cardiol, 2012;33(2):354-6. https://doi. org/10.1007/s00246-011-0131-5

4. Abadir S, Fournier A, Dubuc M, Khairy P. Atrial flutter and fibrillation in the young patient without congenital heart disease. Progr Pediatr Cardiol, 2013; 35(1):41-8. https:// doi.org/10.1016/j.ppedcard.2012.11.006

5. Crochelet AS, Jacquemart C, Massin M. Repeated electrical cardioversions and amiodarone for recurrent neonatal atrial flutter. Arch Pediatr, 2015;22(10):1032-4. https://doi.org/10.1016/j.arcped.2015.06.006

6. Jone PN, Schowengerdt Jr KO. Prenatal diagnosis of congenital heart disease. Pediatr Clin NAm, 2009;56:(3)70915. https://doi.org/10.1016/j.pcl.2009.04.002
7. Jaeggi E, Öhman A. Fetal and neonatal arrhythmias. Clin Perinatol, 2016;43(1):99-112. https://doi.org/10.1016/j. clp.2015.11.007

8. Woo J, Khan O, Caldarelli L, Williams P. Tachycardia in the neonate. Pediatr Ann, 2015;44(10):e247-50. https://doi. org/10.3928/00904481-20151012-09

9. Pike JI, Krishnan A, Kaltman J, Donofrio MT. Fetal and neonatal atrial arrhythmias: an association with maternal diabetes and neonatal macrosomia. Prenat Diagn, 2013;33(12):1152-7. https://doi.org/10.1002/pd.4210

10. Kwok SY, Davis AM, Hutchinson D, Pflaumer A. Successful ablation of refractory neonatal atrial flutter. Heart Rhythm Case Rep, 2015;1(4):245-8. https://doi. org/10.1016/j.hrcr.2015.03.010

11. Garson Jr A, Bink-Boelkens M, Hesslein PS, Hordof AJ, Keane JF, Neches WH, Porter CJ. Atrial flutter in the young: a collaborative study of 380 cases. J Am Coll Cardiol, 1985;6(4):871-8. https://doi.org/10.1016/ s0735-1097(85)80497-6

12. Wacker-Gussmann A, Strasburger JF, Srinivasan S, Cuneo BF, LutterW, Wakai RT. Fetal atrial flutter: electrophysiology and associations with rhythms involving an accessory pathway. J Am Heart Assoc, 2016;5(6):e003673. https:// doi.org/10.1161/JAHA.116.003673 
13. Moller JH, Davachi F, Anderson RC. Atrial flutter in infancy. J Pediatr, 1969;75(4):643-51. https://doi.org/10.1016/ s0022-3476(69)80461-0

14. Rowland TW, Mathew R, Chameides L, Keane JF. Idiopathic atrial flutter in infancy: a review of eight cases. Pediatrics, 1978;61(1):52-6.

15. Casey FA, McCrindle BW, Hamilton RM, Gow RM. Neonatal atrial flutter: significant early morbidity and excellent long-term prognosis. Am Heart J, 1997;133(3):302-6. https://doi.org/10.1016/s0002-8703(97)70224-2

16. Texter KM, Kertesz NJ, Friedman RA, Fenrich Jr AL. Atrial flutter in infants. J Am Coll Cardiol, 2006;48(5):1040-6. https://doi.org/10.1016/j.jacc.2006.04.091

17. Magalhães LP, Guimarães ICB, Melo SL, Mateo EIP, Andalaft RB, Xavier LFR, et al. Diretriz de arritmias cardíacas em crianças e cardiopatias congênitas SOBRAC e DCC - CP. Arq Bras Cardiol. 2016;107(1Supl.3):1-58. 